\title{
СПЕЦКОНТИНГЕНТ КЕРЧЕВСКОГО СПЛАВНОГО РЕЙДА В БОРЬБЕ ЗА ПОБЕДУ В ВЕЛИКОЙ ОТЕЧЕСТВЕННОЙ ВОЙНЕ
}

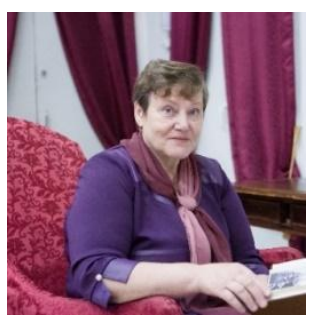

Е.П. Куртенок,

экскурсовод Чердынского краеведческого музея им. А.С. Пушкина, Чердынь kurtenok-e@mail.ru

Аннотация. На основе архивных материалов и прессы говорится о работе Керчевского сплавного рейда в 1941-1945 гг. Рейд выполнял заказ Государственного комитета обороны СССР по заготовке и сплаву спецдревесины - авиасосны, оружейной болванки, пантонника, палубника и фанеры. Основной спецконтингент работников рейда - депортированные, трудпоселенцы и спецпереселенцы. Они жили и работали в очень тяжелых условиях, без нормального питания и медицинской помощи, полураздетые и полуголодные заготавливали и сплавляли лес. Получение в начале Великой Отечественной войны спецзаказа изменило отношение к рабочей силе, которую теперь нужно было беречь, так как с уходом мужчин в действующую армию работников стало не хватать. Самоотверженный труд этих людей помог приблизить победу над врагом, а их имена навечно вписаны в историю знаменитого рейда.

Ключевые слова: спецпоселок, спецконтингент, трудармейцы, депортированные, война, рейд, сплав, древесина, бригада, норма, план.

\section{SPECIAL CONTINGENT OF THE KERCH RAFTING RAID IN THE STRUGGLE FOR VICTORY IN THE GREAT PATRIOTIC WAR}

\author{
Elena Kurtenok, \\ guide of the Cherdyn Local \\ Museum named after A.S. Pushkin, Cherdyn \\ kurtenok-e@mail.ru
}

\begin{abstract}
On the basis of archival materials and the press, it is said about the work of the Kerch rafting RAID in 1941 - 1945. Reid fulfilled the order of the state Committee of Defense (GKO) of the USSR for the prepara-
\end{abstract}


tion and alloy of special wood - aircraft carrier, weapon blanks, pantonnik, deck and plywood. The main special contingent of RAID workers are deportees, labor settlers, and special settlers. They lived and worked in very difficult conditions, without proper food and medical care, half - naked and half starved, harvested and rafted wood. Getting a special order at the beginning of the great Patriotic war changed the attitude to the labor force, which now had to be protected, since with the departure of men to the active army, there were not enough workers. The selfless work of these people helped bring victory over the enemy closer, and their names are forever inscribed in the history of the famous RAID.

Keywords: special settlement, special contingent, labor soldiers, deportees, war, RAID, alloy, wood, brigade, norm, plan.

В конце 20-х гг. в СССР активно начинает развиваться лесная промышленность. Чердынский край, богатый строевым лесом, одна из первых территорий Среднего Урала, где стали создаваться лесозаготовительные предприятия и сплавные конторы. В 1932 г. на реке Каме был организован Керчевский сплавной механизированный рейд. Первоначально в 1931 г. было заложено спецпоселение для репрессированных - людей, высланных из разных регионов страны для работы на заготовке и сплаве древесины. Через год открыта сплавная контора, немного позднее ставшая рейдом, который вошел в состав подразделений Усольлага. Поселок свое название получил от близлежащих деревень Верхнее и Нижнее Керчево. Строили его сами переселенцы. В 1932 г. в посёлке Керчевском проживало 500 человек. Вероятно, это была вторая массовая категория репрессированных по политическим мотивам - крестьяне, высланные с места жительства в ходе кампании «уничтожения кулачества как класса». Люди разных национальностей и из разных областей и республик СССР прибывали в Чердынский район семьями. Это татары, башкиры, болгары, немцы, финны, белорусы, украинцы. Зимой их доставляли гужевым транспортом, по «большой воде» - на пароходах и баржах. Прежде чем спецпереселенцы направлялись на рейд, они находились в других спецпоселках или временно размещались в Чердыни. Иногда неделями жили у костра под открытым небом, пока не получали распределение на поселение. В весенне-осеннее время такие ночевки были сносными. Но зимой многие уже не просыпались, ослабленные и больные умирали, хоронили их прямо в снегу. Умирали и от заразных болезней - сыпного тифа, дизентерии, скарлатины, которые распространялись среди спецпереселенцев очень широко. Ме- 
дицинская помощь в дороге людям не оказывалась, да и в поселках она была недостаточной или там вообще не было медработников.

На 1 января 1941 г. в поселке Керчевском было уже 609 человек из 209 семей, в том числе мужчин - 202, женщин - 223, детей до 16 лет - 184. Все они состояли на учете спецпоселений с обязательной ежемесячной отметкой в Чердынской райкомендатуpe. На 1 марта 1941 г. в Керчевском числилось уже 1756 семей 5899 человек [1, с. 107].

С 1 января 1945 г. открылась спецкомендатура НКВД в самом поселке Керчевском, вторая спецкомендатура НКВД находилась в спецпоселке Лесоруб Чердынского района. Из этого поселка поселенцев направляли на Керчевский рейд. Трудармейцы и переселенцы проживали в бараках, территория охранялась военными. За пределы проживания без пропуска выходить не разрешалось.

Жили в бараках все вместе - и семейные, и одинокие люди. Место проживания разделялось простыней. Работали по 10-12 часов, зимой на заготовке леса по пояс в снегу, с весны на сплотке древесины по пояс в воде. Грязные столовые, плохое питание и бытовые условия, тяжелый труд приводили к разным заболеваниям и травмам, а порой к инвалидности и смертности. Многие не выдерживали такой жизни и совершали побеги с производства. Их находили и привлекали к судебной ответственности. Дисциплина для работников рейда была строгая независимо от того, на каком участке они работали: на сплаве, в конторе, в мастерских или на телеграфе. За опоздание на работу на час привлекали к ответственности по указу от 26 июня 1940 г., и дела на таких сотрудников передавались в суд. С рабочих рейда, отбывавших трудповинность, удерживалось $5 \%$ от заработной платы в пользу НКВД. С тех, кто освобождался от трудповинности, это удержание прекращалось [2, оп. 2, д. 4, с. 4].

К началу Великой Отечественной войны Керчевский сплавной рейд - самое крупное предприятие Чердынского района. Рейд занимался обвязкой в плоты молевого леса, сплавлявшегося по реке Каме и ее притокам. В структуре рейда было три участка: Тюлькинский, Керчевский и Бондюжский, два подучастка: Барановский и Коэптынский. Позднее территория рейда протянулась на 330 км, и в его состав входило шесть основных участков с четырьмя подучастками. Рейд был комплексным сплавным предпри- 
ятием, которое кроме леса имело еще и подсобные производства: строительный участок, механические мастерские для ремонта речного флота, автомашин и тракторов, электростанцию, лесопильный завод, гужевой транспорт для хозяйственных работ, радиостанцию и телефонную связь с двумя коммутаторами, жилищнокоммунальное хозяйство. В 1940 г. сплотка древесины по Керчевскому рейду составила $805,8 \mathrm{~m}^{3}$. С началом боевых действий на территории СССР рейд получил правительственное задание на отбор спецдревесины - авиасосны, оружейной болванки, фанеры, пантонника и палубника. Объем заготовленной и сплавленной древесины увеличился до 978,3 $\mathrm{m}^{3}$.

Рабочих на рейде не хватало всегда, а с уходом на фронт мужчин эта проблема стала еще насущнее. Призванных в РККА мужчин заменили женщины, девушки и подростки в возрасте 15-16 лет. В первый военный сплавной сезон они должны были освоить многие мужские специальности без отрыва от производства. Под руководством опытных специалистов им пришлось осваивать работу бункерщиков, матросов, мотористов катеров, шкиперов судов и рулевых, сортировщиков, фактуровщиков сплоточных машин, трактористов, шоферов, сплотчиков, вальщиков, такелажников, сплавщиков-сортировщиков, токарей, слесарей, машинистов сплоточных агрегатов. «В целях пополнения состава мотористов и рулевых флота, а также мотористов сплоточных агрегатов с 4 июля с/г организовать практическую учебу с женщинами, для чего последних прикрепить по катерам и агрегатам», - из майского приказа 1941 г. по Керчевскому рейду [2, оп. 2, д. 3, с. 47].

С 15 августа 1941 г. были организованы краткосрочные теоретические курсы мотористов с учениками, прошедшими практическую учебу. Занятия проводились с 7 часов вечера до 12 часов ночи. Курсантов использовали на сплавных работах по пять часов в сутки.

Работа сплавщиков была не только тяжелая, но и ответственная. Нужно было следить за правильным отбором спецдревесины. «Отобранная и счаленная спецдревесина не должна стоять незагруженной не более одних суток. Для ее формовки необходимо организовать отдельный прикол, чтобы ни в коем случае она не смешивалась с другими сортиментами древесины», - из приказа по рейду $[2$, оп. 2 , д. 3 , с. 56]. Дирекция рейда стимулировала работ- 
ников за ответственное отношение к своим обязанностям. За каждое отобранное из гражданской древесины бревно авиасосны выплачивалось 3 руб., за каждое бревно пантонника или палубника 2 руб.

В августе 1941 г. началась скатка древесины, осевшей на песках. Ее нужно было провести в краткие сроки, до первых заморозков. Рабочих рук не хватало. Руководство рейда обратилось в поссовет с просьбой провести трудмобилизацию служащих и рабочих во всех учреждениях и послать их на скатку древесины. Кроме этого, в рейде были сняты рабочие, служащие со всех подсобных работ и капстроительства, служащие рейдовой и участковой конторы и направлены на скатку древесины, осевшей на песках в плесе от Коэптов до Керчево. За обеспечение продвижения древесины через перекаты и чистку песков от древесины, за сверхурочную работу сплавщикам платили дополнительно. «Установить на скатке древесины, формировке, в кузнечном цехе, погрузке и сортировке 12-часовой рабочий день. Производить оплату за дополнительные 2 часа, как сверхурочные, в полуторном размере. Сортировка и погрузка должна обеспечить ежедневный план в 17 тысяч ф/м. Техруку участка отрегулировать рабочее время так, чтобы каждый рабочий отработал 12 часов в день. Систематически следить за погрузкой, сортировкой, формировкой и своевременной отбуксировкой древесины оборонного значения. Если ответственные за зачистку не обеспечат выполнение плана, к ним будут применены самые суровые меры», - из приказа по рейду от 15 августа 1941 г. [2, оп. 2, д. 3, с. 77].

В сезон сплава 1942 г. на Керчевском сплавном рейде работали 56,8\% женщин от общего числа работников. Все они трудились добросовестно и перевыполняли дневные нормы. Газета «Северная коммуна» писала: «Женские бригады Бартовой, Кравчук, Мартынюк, Каминской, Носковой выполняли дневные - сменные и в целом месячные задания от 100 до $150 \%$. Много женщин в период навигации работали мотористами и помощниками мотористов на катерах и агрегатах и хорошо освоили эти профессии Ходаковская Анна, Борщ Серафима, Окунь Лидия, Колпакова Любовь, Синькова Парасковья. С окончанием навигации все эти женщины перешли на подготовительные ремонтные работы мотомашин и 
двигателей. Выполняют разборочные и слесарные работы по машинам» [3, № 5, 17 января 1943 г.].

Дни успехов Красной армии зимой 1943 г. Керчевский рейд отмечал трудовыми достижениями. «Производительность труда повысилась на $11,3 \%$. Отдельные рабочие и бригады, взяв обязательства к XXV годовщине Красной армии, с честью их выполняли и перевыполняли. Электросварщик Навродский брал обязательство выполнить дневные нормы не ниже 300 \%. За январь месяц со своей ученицей Петуховой Навродский дал по $363 \%$. Кузнецы Фарион и Буйницкий дали выработку за январь 208-264 \%, слесарь Солодилов - $247 \%$, токари Смирнов и Перминова - 196238 \%. Бригада Маркова в числе пяти человек среднюю выработку дала $218 \%$. На ремонте несамоходного флота бригада Дураченко в числе семи человек дала за январь $245 \%$, на выделке древесины бригады Куренковой в числе 12 человек дали среднюю выработку 238 \%. Эти две бригады премированы директором по 800 рублей каждая. Женские бригады Мартынюк и Кравчук дали выработку $163 \%$. Сейчас эти бригады осваивают новые мужские, более сложные работы - строят опорные точки для сетки. Бригада Немковича на постройке гаванских плиток дает $221 \%$, Клеманского 203 \%, Черных Христины - 199 \%. Бригада Крикун Марии на заготовке газочурки дает $204 \%$, бригада Кучмина - $200 \%$, бригада Дарган - $185 \%$, Гуимова - 177 \%», - сообщает районная газета [3, №12, 14 февраля 1943 г.].

Участвовал рейд и в организации помощи бойцам. Еще в августе 1941 г. в районе начался сбор теплой одежды для Красной армии. На фронт отправляли посылки с валенками, шапками, тулупами, рукавицами. В 1943 г. коллектив Керчевского рейда направил в Красную армию 17 посылок общим весом 283 кг. Среди подарков были печенье, шоколад, папиросы, табак, кисеты, носовые платки, полотенца, носки, сушеные овощи, бумага, карандаши и одеколон.

За хорошие производственные показатели в марте 1943 г. Керчевскому рейду было вручено переходящее Красное знамя ВЦСПС и Наркомлеса. Эти успехи были достигнуты неимоверным трудом сплавщиков.

30 сентября 1943 г. рейд закончил сплав на две недели раньше, несмотря на то, что сплавные работы проходили при 
меньшем количестве рабочих, чем в 1942 г. «С начала сезона до 1 октября было сплочено 1166882 фестметра древесины. Средняя погрузка в сутки за сезон составила 11113 фестметров. Генеральная зачистка была проведена в сжатые сроки с небольшим количеством рабочих. Подавляющее большинство рабочих систематически перевыполняли нормы. Средняя производительность труда на рейде за сезон составила 135-148 \%. Только с мая по сентябрь по Керчевской запани было премировано 265 чел. Крикун Григорий и Дарган премированы по пять раз каждый, Гриценко и Гордеев по четыре раза, Евлевская, Бабенко, Немкович по три раза каждый», пишет корреспондент районной газеты [3, 21 октября 1943 г.].

В этом году рейд сплотил $1146,3 \mathrm{~m}^{3}$ древесины. По итогам года он вышел победителем во Всесоюзном социалистическом соревновании среди лесных предприятий. Коллективу рейда в начале 1944 г. было вручено переходящее Красное знамя Государственного комитета обороны (ГКО).

В связи с тем, что с началом Великой Отечественной войны рейд получил задание ГКО по отбору и сплаву спецдревесины, выполнение которого было обязательным при любых условиях, стало меняться отношение к спецконтингенту, так как это была основная рабочая сила. Передовиков производства стали поощрять премиями, следить за санитарным состоянием столовых и качеством питания. Проводилась и профилактика инфекционных заболеваний.

С 19 февраля 1944 г. для выполнения правительственного задания на всех работах рейда установили рабочее время с 8 часов утра до 7 часов вечера с перерывом в середине работы на один час. С 8 июля по Керчевской погрузочно-сортировочной сетке руководство рейда ввело дополнительное премирование на следующих условиях: «1. Бригадам грузчиков и сортировщиков, работающих на машинах "Блокстадт" и "Снеткова": а) При выполнении плана погрузки за пятидневку выплачивать премию в сумме 2000 руб., 5 л водки и 500 г табака за наличный расчет. б) При перевыполнении плана погрузки на $120 \%$ и выше выплачивать премию 4000 руб.,10 л водки и 1 кг табаку, два хлопчатобумажных костюма. 2. Бригадам грузчиков и сортировщиков, работающим на машинах «ВКЛ»: а) При выполнении плана погрузки за пятидневку выплачивать премию в сумме 1000 руб., 2 л водки, 300 г табаку за наличный расчет. б) При перевыполнении плана погрузки на 
120 \% и выше выплачивать премию 1500 руб., 3 л водки, 500 г табаку и один х/б костюм за наличный расчет.

3. Бригадирам грузчиков и сортировщиков работающим на рацстанках:

a) При выполнении плана сплотки за пятидневку выплачивать премию в сумме 200 руб., 1 л водки за наличный расчет. б) При перевыполнении плана на 120 \% и выше выплачивать премию 500 руб., 1,5 л водки за наличный расчет.

4. Бригадам, работающим на разборке затора и выпуске леса из гавани:

a) При выполнении плана погрузки за пятидневку выплачивать премию 2500 руб., 5 л водки и 1 кг табаку за наличный расчет. б) При перевыполнении плана на 120 \% и выше выплачивать премию 3000 руб., 10 л водки, 2 кг табаку и 2 х/б костюма за наличный расчет. 5. а) Мастерам за выполнение пятидневного плана погрузки секции выплачивать премию в сумме 400 руб., 1 л водки. б) При перевыполнении плана на 120 \% и выше выплачивать премию 600 руб., 1,5 л водки. 6. По решению рейда бригада, которая является победителем в соцсоревновании и держит переходящее Красное знамя рейда, получает ежедневно дополнительно одно мясное блюдо каждому рабочему бригады», - из распоряжения по Керчевскому рейду от 8 июля 1944 г. [2, оп. 2, д. 6, с. 47].

В середине лета создалась тяжелая ситуации с поступлением древесины в запань и угроза невыполнения сплотки. Руководство рейда с 1 августа 1944 г. отменило выходные дни для рабочих запани. Исключение делалось только в том случае, если смена ежедневно выполняла план в 10000 фестметров. В связи с принятым решением у сортировщиков удлинялся рабочий день на один час. А всех служащих управления рейда, мехмастерских, подсобного хозяйства, лесозавода и коммунального хозяйства, ОРСа ежедневно со 2 августа после окончания своей работы обязали выходить с баграми на подачу древесины из запани. Работали они в гавани до 9 часов вечера. До этого же времени работали детские ясли и детсад, для детей было установлено «соответствующее питание».

В 1944 г. Керчевский рейд вышел в число передовых предприятий лесной промышленности. За хорошую работу в августе и сентябре 1944 г. рейду присудили переходящее Красное знамя Государственного комитета обороны СССР. За работу в октябре и ноябре этого же года рейд получил вторую премию, и ему было присуждено переходящее Красное знамя треста «Камлесосплав» и Обкома Союза леса и сплава [3, №1, 4 января 1945 г.]. 
В этом же году в поселок прибыли депортированные по национальному признаку и как бывшие в немецкой оккупации семьи болгар, татар и немцев из Крыма. Часть депортированных была размещена в спецпоселках Лесоруб и Лобырь, часть временно разместилась в лесотехникуме Чердыни. Позднее семьи была разделены и отправлены в разные места. «Нашу семью разделили так: брата, 2 сестер, дядю и его дочь отправили в Керчево, а меня, мать и брата отправили в Лесоруб. В начале 1947 г. нас также перевели на Керчевский рейд», - из воспоминаний Боровик (Велевой) Анны Ивановны [1, с. 157].

Прибывших с южных территорий переселенцев «косила» цинга. Руководство рейда принимало особые меры по ее профилактике. «В целях предотвращения цинготных заболеваний контингента рабочих рейда, обязываю начальника ОРСа (отдел рабочего снабжения) Федорову организовать изготовление витаминизированного кваса с настоем хвои. Напиток ввести в обязательный пищевой рацион рабочих и отпускать в столовых одновременно с подачей пищи. Для прочего населения рейда, не пользующегося услугами столовых, организовать продажу напитка через торговую сеть. Провести массовую разъяснительную работу по этому вопросу среди населения поселка», - из февральского приказа по рейду в 1945 г. [2, оп. 2, д. 6, с. 100].

С мая 1945 г. ввелась новая система питания спецконтингента, и по рейду был издан такой приказ: «В связи с новой системой дифференцированного питания ввести с 20 мая 1945 г. общий порядок общественного питания: А) Завтрак из одного блюда - первого, обед из двух блюд - первого и второго, ужин из двух блюд первого и второго. Б) Дополнительное питание по талонам второго горячего питания предоставлять в обед. В) Помимо вышеуказанного за счет децресурсов краснознаменной бригаде, работающей на прямом производстве, ежедневно приготовлять особые блюда, приравненные к литерному питанию. Г) Нормы закладок и месячного питания установить в соответствии с расчетом потребности основных продтоваров. Запретить отпуск обедов из столовых всем непроизводственным и неплановым контингентам. Д) Снабжение детей военнослужащих и переселенцев в количестве 600 чел. (300 детей в/служ. и 300 чел. - дети переселенцев) согласно разрешения ОБЛУРСа (Областное управление рабочего снабжения прим. aвm.) производить по детским нормам рабочих поселков исключительно через магазины и ларьки в порядке сухого пайка по 
спискам, подписанным начальником или замом ОБЛУРСа и председателем Райкома Союза» [2, оп. 2, д. 6, с. 26].

Начальникам сплавучастков было приказано: «Обеспечить серьезную организацию собственного лова рыбы. Установить следующие задания по лову на период мая - июля 1945 г.: участок Керчево не менее 1200 кг, участок Бондюг - 900 кг, участок Коэпты - 900 кг», - из майского приказа по рейду [14, с. 26].

Поступление принудительной рабочей силы на рейд продолжалось и после окончания войны. Со спецучета эту категорию людей стали снимать только с 1956 г., и у них появилась возможность вернуться на свою историческую родину. Многие бывшие трудармейцы и депортированные уехали. Но оказалось, что на родине их никто не ждал, работу им не предлагали, жить было негде, так как в их домах и квартирах жили другие люди. И почти все вскоре вернулись назад в Чердынский край, где прошла значительная часть их жизни.

Самоотверженный труд депортированных, трудпоселенцев и спецпоселенцев помог приблизить победу над врагом, а их имена навечно вписаны в историю знаменитого рейда. Бригадир лесопункта рейда И.В. Гордеев был удостоен в 1966 г. звания Героя Социалистического Труда. Этого же звания удостоилась в 1971 г. бригадир сортировщиков рейда Н.И. Тимошенко.

\section{Список источников}

1. Документальные материалы и воспоминания репрессированных / сост. Т.А. Крюк; Чердынский краеведческий музей (ЧКМ). - Чердынь, 2007. - 107 с.

2. Отдел по делам архивов администрации Чердынского муниципального района.

3. Районная газета «Серная коммуна» // Чердынский краеведческий музей. 